\title{
A INSERÇÃO DA EDUCAÇÃO AMBIENTAL CRÍTICA NA ESCOLA VIA EXTENSÃO UNIVERSITÁRIA
}

\author{
THE INSERTION OF CRITICAL ENVIRONMENTAL EDUCATION IN THE SCHOOL VIA \\ UNIVERSITY EXTENSION
}

\author{
Maira Rocha Figueira' \\ Maria Jacqueline Girão Soares de Lima² \\ Sandra Lucia Escovedo Selles ${ }^{3}$
}

\begin{abstract}
Resumo: Apresentamos os resultados de uma pesquisa sobre a inserção da Educação Ambiental (EA) crítica em duas escolas públicas municipais do Rio de Janeiro, mediada por um projeto de extensão universitária. Nosso objetivo foi identificar limites e possibilidades da inserção da vertente crítica da Educação Ambiental na educação básica. Grupos focais foram realizados com professores que participaram do projeto. Os docentes entrevistados na pesquisa reconhecem a relevância da Educação Ambiental na escola e procuram adequar suas práticas a diferentes contextos sócio educativos. Considerando três macrotendências da Educação Ambiental (conservacionista, pragmática e crítica), julgamos que, ao ser recontextualizada na escola, a EA apresenta uma mescla de concepções, mobilizadas de acordo com diversas demandas escolares. Apostamos no potencial da extensão para o fortalecimento da EA crítica na escola, na promoção de diálogos e troca de saberes entre os sujeitos das instituições envolvidas e na busca da superação das realidades socioambientais.
\end{abstract}

Palavras-chave: Educação Ambiental crítica. Extensão. Formação continuada de professores.

\begin{abstract}
We present the results of a research on the insertion of critical Environmental Education in two municipal public schools of Rio de Janeiro, mediated by a university extension project. Our objective was to identify limits and possibilities for the insertion of the critical component of Environmental Education in basic education. Focal groups were held with teachers who participated in the project. The teachers interviewed in the research recognize the relevance of Environmental Education in school and seek to adapt their practices to different socio-educational contexts. Considering three macro trends of Environmental Education (conservationist, pragmatic and critical), we believe that, when recontextualized in school, Environmental Education presents a mixture of conceptions, mobilized according to various school demands. We believe in the potential of extension for the strengthening of critical Environmental Education in school, in the promotion of dialogues and the exchange of knowledge between the subjects of the institutions involved and in the search for overcoming socio-environmental realities.
\end{abstract}

Keywords: Critical environmental education. University extension. Teachers further education.

\section{INTRODUÇÃO}

Este artigo examina limites e possibilidades da inserção da vertente crítica da Educação Ambiental (EA) no Ensino Fundamental a partir dos resultados de uma pesquisa realizada com duas escolas públicas do município do Rio de Janeiro. A produção dos dados teve como foco oficinas de formação continuada e outras atividades que integravam um projeto de extensão universitária. Grupos focais foram realizados com professoras e professores de escolas parceiras do projeto, visando discutir e aprofundar sentidos atribuídos pelos participantes nas atividades e proposições destas oficinas.

A opção por tomar a EA crítica no contexto escolar tem apoio em estudos realizados há algumas décadas no Brasil e no exterior. Por exemplo, Kaplan (2011a) considera que a partir da entrada das

\footnotetext{
${ }^{1}$ Professora da Rede Municipal de Maricá. E-mail: <maira.figueira@hotmail.com>

2 Professora do departamento de Didática da Faculdade de Educação da Universidade Federal Fluminense. <giraojac@gmail.com>.ORCID: <http://orcid.org/0000-0003-4419-3468>.

3 Professora Titular da Universidade Federal Fluminense. E-mail: <escovedoselles@gmail.com>. ORCID: <http://orcid.org/oooo0002-7921-0478>.
} 
discussões relacionadas à Educação Ambiental na esfera pública e da aprovação da Política Nacional do Meio Ambiente (PNMA, lei $n^{\circ}$ 6.938/81), a qual institui o Sistema Nacional de Meio Ambiente (SISNAMA), a Educação Ambiental foi, pela primeira vez, explicitada como uma necessidade em todos os níveis de ensino. Um dos princípios destacados foi a Educação Ambiental voltada para a comunidade, com vistas à capacitação e à participação ativa nos debates e práticas relativas ao meio ambiente. A Constituição Federal de 1988 vai no mesmo sentido quando destaca no capítulo VI "Do Meio Ambiente", inciso VI, em seu art. 225, a necessidade de "promover a Educação Ambiental em todos os níveis de ensino e a conscientização pública para a preservação do meio ambiente". Finalmente, em 1991, o Ministério da Educação assume que todos os currículos nos diversos níveis de ensino deverão contemplar conteúdos de EA (BRASIL, 1991, Portaria 678 de 15/5/1991).

Cabe ressaltar que, na institucionalização da EA escolar, esta é frequentemente tratada como um conteúdo homogêneo e consensual, silenciando, desta forma, as disputas tanto na compreensão do que vem a ser a EA escolar quanto em sua constituição como campo de pesquisa. Assim, prevalecem, muitas vezes, as perspectivas hegemônicas que circulam nos meios de comunicação de massa ou as de determinados grupos com maior inserção em instâncias deliberativas. Para uma melhor compreensão deste fato, faz-se necessário um esclarecimento a respeito das disputas internas do campo.

Na perspectiva de Layrargues e Lima (2014), a EA pode ser entendida como um campo social formado por atores que compartilham um núcleo de valores comuns, mas com diferenças em relação às abordagens políticas, pedagógicas e epistemológicas. Para os autores, o campo da EA “já é atualmente reconhecido como multifacetado, composto por inúmeras correntes político-pedagógicas, mesmo que apresentando fortes interfaces entre algumas delas" (p. 25). Na tentativa de compreender algumas dessas correntes, Layrargues e Lima reúnem as principais vertentes da EA em três macrotendências: conservacionista, pragmática e crítica.

Ampliando as possibilidades de evidenciar os aspectos multifacetados do campo, Lima (2011) assinala que a pesquisa em Educação Ambiental tem se associado a perspectivas conservacionistas, críticas, eco-socialistas, hermenêuticas, fenomenológicas e, em menor proporção, pós-críticas e pósmodernas, além daquelas que, por apresentarem mais de uma única vertente epistemológica, podem ser consideradas híbridas. No âmbito dessa diversidade, Loureiro (2004; 2006a) e Lamosa (2010) destacam o predomínio de propostas pragmáticas, que defendem um "uso mais racional" dos recursos naturais. Lima (2011) aprofunda este caráter utilitarista, apontando o esvaziamento crítico que veiculam:

Esta concepção, de cunho eminentemente economicista, busca postergar, com medidas de combate ao desperdício, o esgotamento dos recursos (ACSELRAD, 2004a, p. 7), mas aborda de forma tangencial o problema das desigualdades sociais traduzidas no acesso desigual à água, saneamento, habitação em condições de segurança e a outros fatores associados à sobrevivência das sociedades humanas (LIMA, 2011, p. 82).

O presente artigo orienta-se pelo referencial teórico da EA crítica, que Kaplan (2011b) aponta como desdobramento do materialismo histórico-dialético. O autor preocupa-se em definir a EA crítica em contraposição à EA conservacionista, a qual é centrada nas "mudanças de comportamentos, atitudes e valores morais e éticos individuais", pois para o autor, estas mudanças não procuram "denunciar ou combater a estrutura de classes da sociedade na qual tais valores e condicionantes sociais são produzidos e disseminados" (p. 4).

Se a macrotendência conservacionista valoriza a dimensão afetiva na relação homem-natureza e a mudança de comportamentos e atitudes individuais, a EA pragmática, por sua vez, se concentra em pautas como reciclagem, energia limpa, pegada ecológica etc., e não realiza um aprofundamento de ordem política. Cardoso-Costa e Lima (2015) ressaltam que esta vertente "propõe uma Educação para o Desenvolvimento Sustentável e para o Consumo Sustentável, mas sem uma discussão sociopolítica sobre o que seria sustentabilidade, sendo, portanto, uma forma de ação conveniente à ideologia capitalista hegemônica" (p. 3).

Contrapondo-se a essas macrotendências conservacionista e pragmática, autores como Kaplan (2011b) e Layrargues e Lima (2011) argumentam que a EA crítica busca entender os aspectos que 
estruturam a sociedade de classes no capitalismo, considerando os problemas socioambientais em contradição ao modo de produção capitalista, tendo em vista sua superação como requisito para solucionar os problemas socioambientais. Segundo Layrargues e Lima (2011), nessa perspectiva não se concebem "os problemas sociais dissociados dos conflitos sociais" pelo fato de que "a crise ambiental não expressava problemas da natureza, mas problemas que se manifestavam na natureza" ( $p .8$, grifo nosso). Esses autores interessam-se por focalizar "as causas constituintes dos problemas ambientais", que para eles têm "origem nas relações sociais, nos modelos de sociedade e de desenvolvimento prevalecentes (p. 8).

Ainda no âmbito da delimitação epistêmica da EA crítica, para evidenciar o compromisso social dos estudos empreendidos nesta perspectiva, Loureiro (2006b, p. 59) destaca o quanto esta "busca a autonomia e a liberdade humanas em sociedade, redefinindo o modo como nos relacionamos com a nossa espécie, com as outras espécies e com o planeta". Em outras palavras, a questão ambiental é entendida em seus aspectos sociais, políticos, éticos, econômicos e culturais, desvinculada, portanto, de visões comportamentalistas e individualistas que se baseiam em práticas voltadas para mudanças de comportamentos. A perspectiva crítica da Educação Ambiental também defende valores como a equidade, a justiça social e a inclusão, apostando no diálogo entre ciência e cultura popular e valorizando os saberes tradicionais.

Nesses aspectos, enfatizamos o potencial da escola como instância de produção de uma Educação Ambiental emancipatória, pois, se de um lado essa instituição pode atuar na formação dos valores e conhecimentos que servem à dominação de classes, de outro, se constitui como um espaço de disputas, lutas e resistências por outros projetos educativos, por conhecimentos que sirvam às lutas sociais, por relações sociais, contrapondo-se à opressão de classe, etnia, gênero etc. (KAPLAN, 2011b). Na contradição entre conservação e resistência, explicita-se o caráter produtivo da escola como espaço de práticas que contribuam para um entendimento crítico das desigualdades sociais. Neste sentido, Maia (2014) considera ser preciso superar a concepção de escola a serviço da lógica do capital para que haja um enfrentamento à organização das relações sociais, e consequentemente, aos diversos problemas socioambientais. E o melhor lugar para tal enfrentamento pode ser a própria escola - ainda que de forma não direta, para não recair na ilusão liberal de que esta instituição muda a sociedade -, visto que

Do interior da própria escola podem partir as iniciativas de superação da ideologia da educação para o mercado, indo além, formar para o trabalho que emancipa e não que escraviza. Entretanto, é importante salientar que não é dever da escola resolver tais questões de forma direta, mas levar à apropriação dos instrumentos culturais produzidos socialmente e acumulados historicamente pelos homens [sic] aos indivíduos permitindo, em função dessa apropriação, o enfrentamento da problemática exposta (MAIA, 2014, p. 28, grifo nosso).

Cabe destacar a pertinência da Educação Ambiental crítica na escola, pois se trata de contexto particular com características próprias, diferente da EA desenvolvida nos demais contextos sociais. Este entendimento é reforçado por Lima (2011), que defende a existência de uma Educação Ambiental de tipo escolar, produzida no diálogo entre conteúdos das disciplinas Ciências e Geografia e o campo ambiental. Finalmente, os conhecimentos e práticas de Educação Ambiental escolar podem ser afirmados como portando características próprias, tipicamente escolares, processo detalhado por Oliveira (2007):

Aposto na noção de que a escola vem produzindo ações de Educação Ambiental diferenciadas daquelas produzidas em outros espaços, não sendo possível compreendê-las fora de uma cultura escolar, isto é, como parte do conhecimento escolar. Defendo, então, a hipótese de que tais ações vêm sócio historicamente produzindo, nos ambientes formais, uma Educação Ambiental tipicamente escolar (p. 23-24).

Muitas são as formas e possibilidades de inserção da EA nos contextos escolares, como evidenciadas por Trajber e Mendonça (2007) e outros autores. Mesmo que a maioria das escolas declare 
praticar alguma forma de Educação Ambiental, dificuldades como formação inadequada ou insuficiente, falta de tempo para a elaboração de projetos, currículos com muitos conteúdos e outras dificuldades são enfrentadas por docentes que buscam abordar a temática em suas salas de aula (LIMA, 2007). Apostamos no potencial da Educação Ambiental, e mais precisamente, sua vertente crítica, pois tem importante meio de entrada na escola pelo caminho da extensão universitária, como no caso investigado pela presente pesquisa.

A extensão, por sua vez, surge como uma tentativa de diminuir as distâncias entre os conhecimentos produzidos na universidade e outros espaços sociais por onde circulam modalidades distintas de conhecimentos. O Fórum de Pró-Reitores de Extensão das Instituições Públicas de Educação Superior Brasileiras (FORPROEX, 2012) conceitua a extensão como "um processo interdisciplinar educativo, cultural, científico e político que promove a interação transformadora entre universidade e outros setores da sociedade" (p. 15) e, portanto, tem como diretrizes a indissociabilidade entre ensino, pesquisa e extensão, impacto na formação do estudante e transformação social, entre outras.

No entanto, há diferentes posicionamentos quanto ao seu entendimento, como afirma Silva (2002, p. 155): "desde que emergiu como uma função na universidade, a extensão foi marcada por diferentes concepções e práticas, por dicotomias, contradições e conflitos". Mas, em vários dos seus sentidos, há a tendência de considerá-la como uma forma de ampliar os benefícios da universidade àqueles que não são usualmente atingidos pelas funções de ensino e pesquisa.

Fernandes (2012) destaca a pertinência de se produzir pesquisas que investiguem desdobramentos de projetos de extensão universitária, afinal, não só há poucos estudos que permitam entender os papéis que a extensão vem assumindo para ajudar a universidade pública brasileira a cumprir os seus fins sociais, como também há uma escassez de estudos na Educação que tenham a extensão universitária como objeto privilegiado de estudo. Além do mais, a autora aponta que a formação continuada de professores vem ganhando espaço no meio acadêmico a partir do crescente espaço ocupado pela extensão nas universidades públicas.

O FORPROEX (2012) também recomenda a incorporação da extensão aos programas de mestrado, doutorado ou especialização, de maneira a qualificar as ações extensionistas e a própria pós-graduação, visto que as ações de extensão são mais eficazes quando vinculadas à formação e à geração de conhecimento.

Buscando associar a EA crítica à extensão universitária, o projeto de extensão da UFRJ, foco desta pesquisa, dialoga com estudantes universitários, docentes e discentes de escolas públicas. Sua atuação se volta a produzir materiais didáticos, oficinas e cursos sobre temáticas como consumo, alimentação, sustentabilidade e outras temáticas afins. Os resultados deste projeto e, em particular, as narrativas dos professores participantes acerca das propostas, são examinados neste artigo, no intuito de compreender limites e possibilidades da EA crítica na construção curricular de duas escolas municipais no município do Rio de Janeiro.

\section{METODOLOGIA DA PESQUISA}

Duas escolas municipais foram envolvidas na pesquisa, tendo como sujeitos professores e professoras ${ }^{4}$ que atuam no ensino regular ${ }^{5}$ e na Educação de Jovens e Adultos, nas séries iniciais do Ensino Fundamental e Educação Infantil. A metodologia escolhida foi o grupo focal (DIAS, 2000), que consiste em um momento coletivo em que participantes de determinado grupo interagem entre si, enquanto o pesquisador mobiliza suas questões. Nesse tipo de entrevista coletiva, a argumentação dos participantes vai se construindo e fundamentando coletivamente a partir do embate com as opiniões dos demais. Antes de iniciar o grupo focal, houve o esclarecimento dos seus procedimentos, seguido da assinatura

\footnotetext{
${ }^{4}$ A pesquisa foi submetida ao comitê de ética da Prefeitura do Rio de Janeiro e à Plataforma Brasil, sendo garantido o anonimato dos participantes por meio de termo de consentimento livre e esclarecido.

5 Aqui nos referimos ao "conjunto de atividades de ensino ministradas no âmbito da estrutura educativa estabelecida pela Lei de Bases do Sistema Educativo e que se destinam à maioria dos alunos que frequentam - sistema de ensino dentro dos limites etários previstos na lei". Disponível em <http://smi.ine.pt/Conceito/Detalhes/2884>. Acesso em 2018-27-02.
} 
dos Termos de Consentimento Livre e Esclarecido. O desenvolvimento dos grupos focais se deu com base nos roteiros construídos e foi registrado por meio de gravação com áudio. Subsequentemente foi feita a transcrição das falas para análise.

O número de entrevistados foi definido de acordo com a quantidade de docentes que participaram das atividades do projeto de extensão e ainda seguiam atuando na instituição quando lhes foi proposta a realização de um grupo focal. Na escola de Educação Infantil e séries iniciais, foi preciso montar um cronograma especial de atividades com as turmas para que suas professoras pudessem participar do grupo focal, já que não havia, na instituição, profissionais disponíveis para lhes substituir. O grupo focal foi realizado em setembro de 2016 e contamos com 5 professoras. Tal entrevista será chamada daqui em diante de "grupo focal 1".

$\mathrm{Na}$ outra escola, com o grupo de professores da EJA, realizamos o grupo focal em uma sexta-feira - dia da semana em que as aulas são suspensas para a realização de reuniões e outras atividades pedagógicas. O grupo focal foi realizado em outubro de $2016 \mathrm{com}$ a participação de duas professoras e um professor. Este será nomeado ao longo do texto como "grupo focal 2". ${ }^{6}$

A metodologia do grupo focal foi usada como modo de geração de dados, em um processo de entrevista e discussões coletivas (DIAS, 2000), no qual os docentes puderam falar sobre os desdobramentos que surgiram após a participação no projeto. Por um lado, a intenção foi conhecer as estratégias utilizadas pelos professores num tempo que se sucedeu às atividades realizadas no âmbito do projeto de extensão e, por outro lado, ouvir e compreender como deram sentido a suas práticas, produzindo seu próprio currículo. Com isso, buscamos explorar o potencial e as limitações da EA crítica. No registro do grupo focal as vozes se superpõem, razão pela qual trazemos à análise as falas dos docentes, sem nominar cada um deles. No entanto, como se tratam de dois grupos de escolas com contextos muito diferentes, será explicitado, ao longo da análise, em qual grupo focal se originou cada fala.

\section{Resultados e análise}

$\mathrm{Na}$ análise qualitativa do material foi usada a técnica de análise de conteúdo, definida por Bardin (2011) como um "conjunto de técnicas de análise de comunicação visando obter, por procedimentos sistemáticos e objetivos de descrição do conteúdo das mensagens, indicadores (quantitativos ou não) que permitam a inferência de conhecimentos relativos às condições de produção/recepção destas mensagens" (p. 47).

Dividimos os dados produzidos na pesquisa nas categorias "a EA e o currículo escolar", "currículo e saberes docentes" e "relação universidade escola". Ainda que existam interfaces entre as categorias, sua elaboração permitiu organizar as reflexões dos participantes da pesquisa de modo a contribuir para os campos da educação ambiental, do currículo e da extensão.

\section{A EA e o currículo escolar}

O papel da EA foi entendido como integrado à prática docente, e reconhecidamente presente na escola, conforme a fala registrada no grupo focal 2: "[a EA] é um tema recorrente em todas as escolas, é uma pauta de todo ano letivo". Cabe ressaltar que a autora desta fala é a coordenadora da escola, que tem vasta experiência docente e atua como professora em outras instituições. Tal entendimento está de acordo com o que apontam os levantamentos de Trajber e Mendonça (2007) sobre a universalização das práticas de Educação Ambiental desde o Censo Escolar de 2004. Ainda que estejam integradas à prática, o que sobressai é que os docentes operam com essas temáticas produzindo adaptações ao nível de interesse e compreensão de suas turmas, pois registram que trabalhar a EA é possível mesmo com crianças dos anos iniciais: "a gente pode tratar do mesmo assunto, mas com abordagens diferentes, por exemplo, quando se fala em aquecimento global, o nível de aprofundamento pode ser diferente, mas um

\footnotetext{
${ }^{6}$ Embora o número de participantes neste grupo esteja um pouco abaixo do que defendem muitos autores para esta técnica de entrevista, só foi possível reunir 3 professores. Devido à dificuldade encontrada no agendamento dos participantes deste grupo focal e à riqueza do debate que se deu neste encontro, optamos por inserir o grupo focal 2 como corpus da pesquisa.
} 
mesmo assunto pode ser pertinente em todos os anos" (grupo focal 2). Assim, a integração das temáticas de EA é elaborada no interior da docência, tornando-se parte do currículo construído no cotidiano escolar.

Ao lado das adaptações que os docentes efetuam, a EA é vista para além da abordagem de conteúdos específicos, pois estes também sofrem transformações e atualizações para que possam ser entendidos como ferramentas de transformação social, uma vez que favorecem reflexões sobre os problemas da sociedade atual: "acho que a gente deva trazer conteúdos que estejam ligados ao que nós estamos vivendo no momento, principalmente os problemas" (grupo focal 1). Essas adaptações não se circunscrevem às dimensões da EA associada a conceitos relativos à natureza, pois a questão ambiental, englobando o espaço urbano, parece mais próxima ao universo vivido de uma escola num grande centro urbano como o Rio de Janeiro: “A EA passa por esse viés: quais são os recursos que eu tenho disponíveis que vem da natureza, como trabalhar, e dentro do espaço urbano também, a EA afeta a cidade e não só a mata" (grupo focal 2).

Esses modos de entender a Educação Ambiental, mobilizando a criatividade docente para efetuar adaptações e ajustes de acordo com a faixa etária das turmas e o espaço sócio cultural onde vivem, dão mostras de um entendimento mais amplo e menos instrumental da EA pelos docentes, considerada, assim, como uma questão política pertinente ao ambiente escolar: "a gente não pode perder de vista que tem uma política ambiental, e quando nós estamos dentro de uma escola a gente não se tornou apolítico, não é uma questão partidária, é uma questão do planeta, da 'polis', como é que a gente como sociedade vai vivendo esse mundo" (grupo focal 2).

Não podemos afirmar que essas visões tenham se originado a partir apenas do contato dos docentes com o projeto, mas, na medida em que, nas suas atividades, as temáticas ligadas ao cotidiano sob um viés socioambiental foram abordadas junto às escolas parceiras, e que a perspectiva crítica da Educação Ambiental e o diálogo com conteúdos escolares - sobretudo da disciplina Ciências - foram valorizados, é plausível apontar sua contribuição. Ao articular politicamente os conteúdos das aulas de Ciências, em particular os mais próximos às questões socioambientais, os docentes se aproximam do perfil do professor de Biologia que possui um conjunto de atributos e valores ecológicos, constituindo um parâmetro orientador de escolhas e estilos de vida: os sujeitos ecológicos, conforme conceitua Carvalho (2004).

Esse entendimento também encontra apoio em Campos e Cavalari (2017), quando reconhecem que "professores são, potencialmente, educadores ambientais no ensino formal, mas para que atuem como tal é necessário que ocorra um processo de identificação pessoal e profissional com o ambiental durante a sua trajetória de vida" (p.59). Por outro lado, Trein (2012) nos lembra que, devido à sua origem no campo ambiental e no âmbito de movimentos sociais, a Educação Ambiental se incorporou tardiamente ao campo educativo, com consequências para pesquisas e práticas de EA escolar. Assim,

[...] ao afirmar o ambiental, o campo da EA assume uma perspectiva limitada. É como se a EA olhasse a educação desde um outro campo. Em consequência, ela adquire um caráter prescritivo, enfatizando tarefas que entende que deverão ser cumpridas pela escola e pelos professores. Dessa forma, a EA parece desconsiderar o acervo de conhecimentos já produzidos e sistematizados pela área da educação. (p. 303).

Concordamos com a autora em relação ao aprofundamento do diálogo entre a educação ambiental e a educação, também apontada por Loureiro e Lima (2006). Reproduzimos alguns dos questionamentos apresentados por Trein, que, de certa forma, orientaram essa e outras pesquisas que desenvolvemos. $O$ primeiro deles diz respeito à necessária articulação entre as políticas de educação ambiental e o histórico das políticas públicas de educação. Em seguida, problematiza o entendimento - bastante comum entre pesquisadores da EA - de que os professores "não estão preparados para exercer uma educação ambiental crítica", que desconsidera o "acúmulo de formulações teóricas do campo educacional sobre a formação de professores". O mesmo acontece quando afirmamos o caráter interdisciplinar da EA sem nos apropriarmos das contribuições das pesquisas sobre currículo e didática, "debatidos há décadas na ANPEd, no ENDIPE e outros fóruns acadêmicos" (p. 304). Defendemos, junto com esta autora, que as pesquisas sobre educação ambiental em contextos escolares se apropriem de referenciais teóricos do 
campo da educação, se afastando de críticas aos docentes e identificando estratégias didáticas, saberes e referenciais mobilizados em suas práticas.

Quando a professora sugere que a presença da EA no currículo está estabilizada, enfatiza que "é uma exigência curricular", ou seja, parece reconhecer que é um conteúdo que deve ser incluído no planejamento de todos os docentes, devido à sua importância e à massiva presença em materiais didáticos e projetos, como os cadernos pedagógicos da Secretaria Municipal de Educação, fornecidos às escolas da rede. As falas dos professores que atuam no Programa de Educação de Jovens e Adultos (PEJA), também retratam que há certa flexibilidade no currículo para os debates ambientais, independente da modalidade de escolarização. Destacamos a percepção de flexibilidade na escolha dos conteúdos curriculares tendo em vista o contexto de controle do trabalho docente e dos currículos predominante nas políticas educacionais da última década, voltadas para o cumprimento de metas com vistas à realização de exames (SELLES, 2015). Os professores não atribuem esta autonomia ao fato de o PEJA ser um segmento com mais abertura pedagógica, mas parecem associá-la à natureza das temáticas ambientais: "a gente tem experiência no ensino regular (ensino fundamental 1) e tem essa flexibilidade [enfoque EA] sim". Isso fica ainda mais explícito na seguinte fala:

[o professor] tem a liberdade, quer queira quer não, hoje você pode chegar: eu vou trabalhar um texto com o tema água. Só o título água, você começa a esmiuçar, tá trabalhando toda a alfabetização, leitura e a participação, mas tendo como enfoque que aquela água está fazendo parte do seu dia a dia, você ganha muito (grupo focal 2).

Em busca de compreender a relação entre a Educação Ambiental e a Educação de Jovens e Adultos em documentos oficiais, Paranhos e Shuvartz (2013) concluíram que este vínculo, ainda que de forma tênue, está presente na Constituição Federal do Brasil e na Política Nacional de Educação Ambiental e concluem que a EA na EJA deve levar em consideração o histórico de vida do adulto, do qual as problemáticas ambientais fizeram parte, direta ou indiretamente. Para os autores, a EA comportamental não é a mais adequada para a EJA por não estar embasada nos pressupostos da Educação Popular. Concluímos que a flexibilidade mencionada pelas docentes da presente pesquisa, apesar de não se referir apenas à EJA, encontra apoio nas reflexões destes autores.

Nesse ponto, a pesquisa abre um espaço produtivo para ampliar as reflexões que a presente investigação abrange: o da Educação Ambiental crítica na Educação de Jovens e Adultos, particularmente se identificadas com os estudos de Paulo Freire. Tanto a EJA quanto a EA crítica têm neste autor um referencial importante e ambas compartilham de ideais emancipatórios e de transformação social, como assinalam Figueiredo (2006), que investigou práticas docentes na Educação de Jovens e Adultos "em confronto com uma ecopráxis educativa molhada das contribuições de Paulo Freire" (p. 1). Dickmann e Carneiro (2012), cujo estudo contribui para o desenvolvimento da pedagogia crítica na Educação Ambiental, e Canabarro, Oliveira e Silva (2009), que relacionam conceitos centrais da obra de Paulo Freire com a atualidade de sua contribuição para pesquisas no campo da Educação Ambiental, dentre outros, como podemos contextualizar em Freire (1991):

Você, eu, um sem-número de educadores sabemos todos que a educação não é a chave das transformações do mundo, mas sabemos também que as mudanças do mundo são um quefazer educativo em si mesmas. Sabemos que a educação não pode tudo, mas pode alguma coisa. Sua força reside exatamente na sua fraqueza. Cabe a nós pôr sua força a serviço de nossos sonhos.

Além das considerações curriculares específicas, as falas dos docentes dão destaque ainda a uma dimensão ética - e decisiva - que parece intrínseca ao papel e ao compromisso destes profissionais em promover a EA escolar: "nós professores temos que estar engajados nisso". Entendemos que o engajamento docente não se dissocia do compromisso, o que reforça seu papel na construção da EA escolar, aspecto reafirmado por Oliveira (2007, p. 9), quando conclui que: "uma parcela dos profissionais socialmente preocupados e/ou envolvidos com as questões ambientais tem atuado como docente na Educação Básica". 


\section{Currículo e saberes docentes}

Os entendimentos sobre flexibilidade curricular ou modos de seleção curricular parecem distintos em cada escola. As professoras que atuam no ensino regular se mostram muito preocupadas com as pressões atribuídas ao currículo e reconhecem as limitações impostas à inclusão de tais temáticas no planejamento: "eu particularmente tenho uma dificuldade de agregar isso [atividades de EA] como uma rotina, como uma prática constante na sala de aula, não sei, por essa questão da demanda [curricular] 'tem que ler, tem que escrever"'. Parece que o compromisso com o letramento e com a apropriação de conteúdos matemáticos está amplificado e diretamente vinculado aos primeiros anos de escolaridade em modalidade de ensino voltada a faixas etárias mais precoces, o que dilui o lugar reservado à EA como um tópico específico. A centralidade da leitura e da matemática nos primeiros anos da escolaridade vai requerer dos docentes um ajuste das temáticas de EA a serem exploradas no âmbito desses dois componentes curriculares centrais, possivelmente de forma transversal.

Essas exigências curriculares, mesmo articuladas às atividades rotineiras dos professores, demandam uma atenção que ajuste os conteúdos temáticos da EJA ao perfil de seu corpo discente. Ao reservar um tempo do planejamento para se dedicar a explorar a EA, os professores se mostram atentos para que tal temática se aproxime do público alvo a que pretendem atingir. O reconhecimento deste trabalho de criação docente pode ser compreendido mobilizando lentes teóricas que aproximam currículo e saberes docentes, como discutem Selles e Ferreira (2009), pois permite entender o professor como um criador do currículo, um portador de saberes plurais construídos em sua história de vida, "oriundos da formação profissional e de saberes disciplinares, curriculares e experienciais" (TARDIF, 2014, p. 36).

Mobilizando essa referência destacada por Tardif (2014), cabe assumir que os professores também transformam o conhecimento de referência no interior de suas práticas cotidianas, argumento defendido por Carmo e Selles (2018). Para os autores, mobilizando seus saberes os docentes produzem conhecimento escolar em "modos de fazer" próprios, tecidos no cotidiano de suas práticas pedagógicas. Assumem que há um certo "caráter contingente da ação", no qual "esses 'modos de fazer' explicitam maestrias não ensaiadas, nas quais os professores combinam diferentes dispositivos mediadores, produzindo reconfigurações nas formas de apresentação dos conteúdos" (p.295). Esse entendimento do caráter produtivo do trabalho em sala de aula vai ao encontro das reflexões de Oliveira (2007) quando destaca a especificidade da ação docente e de seus saberes, produzidos por meio do contato com práticas em Educação Ambiental: "lidando com a sua prática e com a pluralidade de conhecimentos que esta envolve, o professor de Ciências e Biologia insere a Educação Ambiental em suas aulas de um modo 'particular', podendo construir práticas diferenciadas das sugeridas oficialmente” (p. 54).

Dessa forma, a adequação a abordagens curriculares mais próximas a habilidades de letramento na infância e à socialização de certos hábitos nesta etapa da vida adquire centralidade nas falas, apontando para um entendimento de que a EA mais adequada às crianças seria aquela normativa $e$ comportamentalista, ao passo que só com uma faixa etária mais avançada seria possível ampliar para uma discussão política, como destaca uma professora:

Quando você trabalha com criança você faz um olhar que tem a ver com a criança, que fica muito no jogar o lixo, não produzir tanto lixo, e quando você chega no campo mais do adulto já existem outros olhares que não só fica no 'não faça isso, não faça aquilo', mas que a gente até amplia pra uma discussão política da questão ambiental (grupo focal 2).

Outro destaque é dado ao planejamento coletivo na escola - em reuniões de estudo - da equipe em conjunto e ao planejamento das especificidades para cada turma: "Quando aqui nós sentamos para pensar, em geral a gente senta e pensa junto e cada um vai fazendo o recorte que corresponde ao seu grupo, que tem leituras diferentes" (grupo focal 2). Assim, são feitas referências ao ajuste curricular, levando em consideração a adequação ao público no sentido do aprofundamento, bem como à seleção de temáticas que toquem ao aluno de alguma forma:

Essa seleção é pedagógica, porque tudo seria importante [...] eu tô aqui analisando o que que nesse momento [é mais importante], porque na escola a 
gente vai ter que fazer uma seleção. [...] senão fica profundo demais e você não alcança o aluno, fica você falando consigo mesmo ou então fica raso demais e a gente fica só no não jogue lixo no chão, que é aquela frase que repete e repete (grupo focal 2).

A atuação do projeto de extensão nas escolas, se por um lado deu suporte às professoras para a ampliação das possibilidades de abordagem curricular - "vocês me trouxeram outros materiais, eu saí da caixinha com outras possibilidades [...] então ampliou um pouco esse repertório" (grupo focal 1) -, também parece ter influenciado nos modos de repensar o planejamento, visto que

na Educação Infantil, a gente está naquelas vivências, nas práticas lúdicas, iniciação no letramento, e tudo o mais, e já com o primeiro ano é aquela coisa sequelada da leitura e da escrita, da matemática, e às vezes a gente enquanto professor não dá abertura para as outras áreas como história, geografia, ciências. E quando vocês estiveram aqui [...] tivemos que repensar o planejamento nesse sentido para estar agregando conteúdos que até então a gente não tinha planejado de trabalhar com eles (grupo focal 1).

Entretanto, esse processo de replanejamento em uma das escolas evidenciou tensões com planejamentos anteriormente realizados, mostrando certo desconforto a influências externas - oriundas de instituições universitárias, por exemplo - quando não dialogam com a realidade da escola. Essas tensões sugerem que a autonomia docente não pode ser desconsiderada na atuação de projetos extensionistas, podendo significar receptividade ou rejeição. $\mathrm{O}$ acolhimento a projetos externos parece depender dos modos de negociação e de possibilidades de construir diálogos: "eu acho que a gente reage mais dessa forma [receptiva] quando a gente vê que realmente tá integrando aquilo que a gente tá falando, tá acrescentando, tá realmente junto com a gente" (grupo focal 1).

\section{Relação universidade/escola}

Nesta categoria, cabe destacar duas contribuições trazidas pela equipe do projeto de extensão, observadas no conjunto das falas dos grupos focais. Já foi amplamente discutido que a EA crítica foi construída nas escolas em diálogo com o projeto. Outra contribuição diz respeito ao papel social desempenhado pela extensão universitária. Um professor da escola de EJA citou o tripé "ensino, pesquisa e extensão", considerando a extensão algo que a universidade dá em troca para a sociedade, onde "você traz o que você aprende e leva a contrapartida que a universidade tem que dar pra sociedade, porque quem está ali naquele banco sentado, alguém está pagando por ele". Dessa forma, ao alertar que "é público, mas é um público que tem o financiamento do próprio cidadão", o professor refere-se a um entendimento que parece ultrapassar uma ação interinstitucional para situá-la em âmbito social: a sociedade de maneira geral dá o suporte que a universidade pública precisa para funcionar, apesar de grande parte da sociedade jamais ser beneficiada ou ter acesso ao conhecimento produzido nestas instituições.

Em outras palavras, evidencia-se o entendimento de que a extensão é uma forma de contextualização acadêmica, ainda que verticalizada, ou seja, é o meio pelo qual a universidade vai levar conhecimentos acadêmicos para fora dos seus limites, como destacado nesta afirmação: "é como se a universidade se estendesse até aquele determinado local/área que ela esteja atuando [...] não deixa de ser conhecimentos acadêmicos que foram trazidos" (grupo focal 1) e assim dá outro sentido a esse conhecimento. Nesta fala explicita-se o direcionamento unilateral dos conhecimentos produzidos historicamente na universidade, pois esta já esteve isolada da sociedade. Caminhando em outra direção, a extensão pode potencializar um diálogo institucional, ainda com centralidade que demonstra hierarquização da universidade, permitindo sua presença na escola, como sugere a professora no grupo focal 1:

Durante um período [teve] essa questão da universidade também estar no seu mundo acadêmico, aquela coisa mais fechada. Eu acho que desde o momento que algumas áreas e alguns grupos têm esse desdobramento de conciliar aquilo que se produz como conhecimento na universidade e trazer como extensão pra 
sociedade de modo geral [...] eu acho que esse conhecimento se ressignifica.

Sendo assim, é inevitável pensar que essa interação da universidade com a sociedade modifica a forma pela qual a primeira situa a direção da produção de conhecimentos, pois no projeto de extensão "é onde você aprofunda mais, traz novas vivências, você sai do acadêmico puro e vai para uma coisa da vivência, da prática, da aplicação daquele estudo, então se faz ali uma nova aprendizagem" (grupo focal 2). Esta fala demonstra um desejo de reciprocidade, importante para nortear a presença da universidade na escola por meio da extensão:

Acaba virando uma via de mão dupla, porque ao mesmo tempo em que o conhecimento é produzido, é aplicado ou tenta ser aplicado. E aí você se depara com uma realidade que pode ser de acordo com aquilo que vocês imaginavam ou totalmente diferente, ou até melhor do que vocês imaginavam antes. E daqui, do resultado que se vê da vivência, [...] isso volta pra lá de uma outra forma e dá chance de outros braços, outros assuntos virem. E a gente de uma certa forma está sempre procurando estar se atualizando, estudando [...] muitos de nós podem até não ter a oportunidade de estar de volta na universidade fazendo um curso, especialização, a gente tem essa oportunidade de estar se atualizando (grupo focal 1).

Assim, a boa intenção dos grupos da universidade que pretendem adentrar na escola não é suficiente para garantir essa troca de conhecimentos, o que adverte para a necessidade de cautela nessas relações e apela para um entendimento não hierarquizado entre essas instituições. É fundamental que sejam levadas em conta as necessidades e as demandas da comunidade em que projetos extensionistas pretendem atuar. Isso não pode significar uma desistência acerca da circulação de ideias, pois mesmo que algumas temáticas não façam parte do planejamento docente prévio, há possibilidades frutíferas em relação à relevância de temáticas a serem introduzidas. Nesse sentido, o pronunciamento docente parece reforçar essa ideia ao se dizer que: "quando vem vocês de fora, é a parada obrigatória, [...] por prazer" (grupo focal 1).

Com relação à pertinência do projeto, as professoras alertam: "de vez em quando chegam uns projetos que a gente considera muito legal, mas que não caminha junto com o nosso planejamento, aí cria um buraco, tipo assim 'pra que que eu tô vendo isso?"' (grupo focal 1). Essa percepção permite concluir que a escola, e por sua vez, seu corpo docente, vão receber os projetos da universidade de acordo com seus interesses. Fundamentalmente, a decisão cabe à escola: "a coordenadora deixou bem claro 'você quer participar?' se dissesse que não, também tem essa liberdade” (grupo focal 1).

\section{CONSIDERAÇÕES FINAIS}

Os resultados da análise do material empírico produzido neste trabalho integram a problemática investigada em torno de dois eixos. O primeiro deles versa sobre o papel da extensão universitária para todos os sujeitos que dela participam: estudantes, professores das instituições educativas e o público escolar, os quais se associam num empreendimento formativo para todos. O segundo eixo insere a EA crítica no debate da incorporação desta perspectiva em produções curriculares de docentes que atuam em escolas com público discente diversificado, junto à condição chamada de regular e a dos alunos jovens e adultos trabalhadores (EJA).

Em relação ao primeiro eixo, o material analisado permite discutir mais detidamente as possibilidades de projetos de extensão e contribui para desconstruir visões utilitaristas destas atividades. Muito além de ser compreendida como uma doação de conhecimentos e práticas produzidos na universidade ou meramente uma prestação de serviços, a análise tecida sobre os resultados produzidos permite reconhecer que a extensão cumpre a função de possibilitar uma rica troca de saberes, a partir do diálogo que provoca entre as instituições envolvidas e os sujeitos que delas participam. Em várias falas registradas no grupo focal, fica evidente não somente o sentido de extensão como uma contrapartida que a universidade disponibiliza para a sociedade, mas especialmente seu sentido inverso: o retorno que a escola oferece para a produção de conhecimentos da universidade, configurando assim uma relação de reciprocidade. Os relatos dos professores reafirmam tais constatações quando assinalam que 0 engajamento docente nessas atividades favorece a ocorrência ou não de práticas de EA. Isto porque 
reconhecem que essas práticas são construídas em processos dialógicos que as atividades de extensão engendram.

Como segundo eixo analítico, cabe destacar em que medida a presente pesquisa contribui para pensar acerca dos limites e possibilidades da EA no contexto escolar. A análise sugere que a combinação entre as diferentes macrotendências - pragmática, conservacionista e crítica (LAYRARGUES e LIMA, 2014) - parece ser parte da recontextualização de tais conteúdos na escola. Em outras palavras, distanciandose de uma visão monolítica ou hierárquica dessas macrotendências, os docentes produzem modos específicos de combiná-las pedagogicamente para garantir a presença da EA no cotidiano da escola e atender às finalidades próprias da escolarização, seja na educação infantil, seja na EJA.

Os resultados também nos autorizam dizer que as características próprias da escola e o contato direto com as necessidades dos alunos provocam rupturas entre a delimitação epistemológica dessas tendências, haja vista que sua formalização se insere em outro contexto de produção e prática. A pesquisa evidenciou ainda que esse processo de recontextualização é operado pelos docentes, se considerarmos que a abordagem pragmática da Educação Ambiental tende a chegar aos professores e alunos pela mídia, livros didáticos e outros meios.

Assim, a possibilidade de discutir nas escolas alguns elementos da perspectiva crítica e perceber indícios nas falas dos professores a respeito dessa outra visão sobre o meio ambiente e a sociedade, já pode ser considerada um indicativo da apropriação docente da EA crítica que baliza o trabalho de extensão. Portanto, se a Educação Ambiental, conforme registrado nas discussões do grupo focal, se encontra presente nas escolas integrando sua agenda, ou ainda se já é possível afirmar, por meio da literatura, que corresponde a uma realidade nas escolas brasileiras (TRAJBER e MENDONÇA, 2007; LIMA et al. 2015), os registros analisados na presente pesquisa apontam a extensão como um caminho frutífero para o trabalho com a EA crítica na escola. Sem dúvida, trata-se de importante contribuição para pesquisas que buscam compreender as diferentes abordagens e perspectivas da Educação Ambiental nas escolas brasileiras, assim como para a compreensão do potencial da extensão no sentido de possibilitar criações e ressignificações curriculares.

Cabe considerar que os resultados da investigação indicam ainda o quanto a EA crítica se ajusta aos públicos das escolas participantes. Por um lado, os professores consideram que a politização das questões ambientais é mais adequada ao contexto de Educação de Jovens e Adultos. Mas, por outro lado, em ambas as escolas foi marcante o desenvolvimento de uma conceituação de meio ambiente que integra os seres humanos e suas relações, como aspecto importante a ser trabalhado junto com outros elementos da natureza, independente de faixa etária ou outras características do público estudantil. Ou seja, se os professores não aderem completamente à EA crítica, por entender que algumas questões desta vertente não se adequam à etapa inicial de escolarização, também não rompem completamente com tal visão de meio ambiente, visto que não só integram outros aspectos da EA crítica, mas também da EA pragmática e comportamentalista, como por exemplo, questões que se colocam sobre água e lixo. Dessa forma, conforme a análise deste trabalho sugere, a compreensão do campo da EA para os docentes parece ter se ampliado, permitindo que mobilizem diferentes conceitos e perspectivas de acordo com suas necessidades e as demandas da escola.

Os resultados desta pesquisa nos permitem argumentar que as pesquisas sobre a EA nos contextos escolares propiciam uma análise das decisões curriculares das equipes pedagógicas, levando em conta a dinâmica de seus contextos sócio históricos e formativos. Deste modo, reafirma-se a produção escolar que se dá ao nível da docência, entendendo os professores como profissionais que têm saberes e concepções construídas na práxis e que estes saberes não são estáticos ou determinados pelos textos das políticas. Na medida em que nos afastamos de concepções desqualificadoras em relação ao trabalho docente, nos aproximamos das proposições de autores como Antonio Novoa (2009), Tardif e (2014), que, em suas pesquisas, identificam não apenas as dificuldades enfrentadas pela categoria, mas também seus movimentos de resistência e a criatividade mobilizada na produção de saberes docentes e de currículo.

Concluímos com a defesa de que a pesquisa que apresentamos contribui para os campos da Educação Ambiental, do currículo e da extensão (e suas interfaces). O trabalho avança no sentido de 
pensar na EA escolar como um conhecimento dinâmico, híbrido, criado espaçotemporalmente por docentes a partir de suas experiências e conhecimentos, bem como do contato com materiais didáticos produzidos na e para a escola (livros, apostilas, cadernos pedagógicos). No que tange aos estudos sobre a relação universidade escola via extensão, o trabalho destaca sua potencialidade na produção de currículos e como espaço formativo e dialógico, aproximando instituições e sujeitos do campo da educação. Por fim, as inovações curriculares identificadas a partir do diálogo entre as instituições envolvidas na parceria aqui apresentada ajudam a pensar o currículo em perspectivas não fixadas em programas, deliberadas externamente à escola ou mesmo à sua revelia. Ao mobilizar concepções de EA crítica por meio de um processo de extensão, foi possível visibilizar sujeitos autores de sua prática, que significam coletivamente suas ações por entre as tensões e dilemas vividos no seu cotidiano escolar.

\section{REFERÊNCIAS}

BARDIN, L. Análise de conteúdo. São Paulo: edições 70, 2011.

CANABARRO, C. L., OLIVEIRA C. T. e da SILVA, M. F. SANTOS. Aproximações entre Paulo Freire e educação ambiental emancipatória: uma análise partindo da ética, da estética, da política e da epistemologia. Rev. eletrônica Mestr. Educ. Ambient. ISSN 1517-1256, v. 23, julho a dezembro de 2009. Disponível em: <https://periodicos.furg.br/remea/article/view/4567> Acesso em 2018-08-11.

CAMPOS, D. B. de; CAVALARI, R. M. F. O professor de Biologia enquanto educador ambiental: delineando o perfil de um caso participar de sujeito ecológico. Revista Pesquisa em Educação Ambiental, vol.12, n.1 p. 58-70, 2017.

CARDOSO-COSTA, G.; LIMA, J. G. S. Educação Ambiental na escola: uma análise das concepções e práticas presentes em relatos de experiência dos Encontros Regionais de Ensino de Biologia RJ/ES. In: VIII Encontro Pesquisa Em Educação Ambiental, 2015, Rio de Janeiro - RJ. Anais VIII EPEA, 2015.

CARMO, E. M.; SELLES, S.E. Modos de fazer elaborados por professores de Biologia como produção de conhecimento escolar. Revista Brasileira de Pesquisa em Educação em Ciências, 18 (1), p. 269-299. Abril de 2018.

CARVALHO, I.C.M. Educação ambiental: a formação do sujeito ecológico. São Paulo: Cortez, 2004.

DIAS, C. A. Grupo focal: técnica de coleta de dados em pesquisas qualitativas. Informação e Sociedade: estudos. v. 10 n. 2, 2000. Disponível em <http://periodicos.ufpb.br/index.php/ies/article/view/330/252>. Acesso em 2018-05-04.

DICKMANN, I. e CARNEIRO, S. M. M. Paulo Freire e Educação ambiental: contribuições a partir da obra Pedagogia da Autonomia. R. Educ. Públ. Cuiabá v. 21 n. 45 p. 87-102 jan./abr. 2012. Disponível em <http://periodicoscientificos.ufmt.br/ojs/index.php/educacaopublica/article/viewFile/334/302>. Acesso em 2018-08-11.

FERNANDES, K. O. B. Currículo de ciências: investigando sentidos de formação continuada como extensão universitária. Dissertação de Mestrado. PPGE/FE/UFRJ, Rio de Janeiro, 2012.

FIGUEIREDO. J. B. As contribuições de Paulo Freire para uma educação ambiental dialógica. $29^{a}$ Reunião Nacional da Anped. 2006. Disponível em: <http://2greuniao.anped.org.br/trabalhos/trabalho/GT22-2184-Int.pdf $>$. Acesso em 2018-08-11.

FORPROEX. Política Nacional de Extensão Universitária. Fórum de Pró-Reitores de Extensão, 2012.

FREIRE, P. A Educação na Cidade. São Paulo: Cortez; 1991.

KAPLAN, L. Análise crítica dos discursos presentes nos documentos que definem a política de Educação Ambiental no Brasil. Dissertação (Mestrado em Educação) - PPGE/FE/UFRJ, Rio de Janeiro, 2011a.

KAPLAN, L. Discursos estruturantes das políticas federais de Educação Ambiental: Estado, sociedade civil, crise socioambiental e o lugar da escola. In: VI EPEA, 2011, Ribeirão Preto. Anais do VI Encontro "Pesquisa em Educação Ambiental" - A pesquisa em Educação Ambiental e a pós-graduação no Brasil, p. 1-15. 2011b.

LAMOSA, R. de A. C. A Educação Ambiental e o novo padrão de sociabilidade do capital: um estudo nas escolas de Teresópolis (RJ). Dissertação de Mestrado, Programa de Pós-Graduação em Educação da UFRJ. 
Rio de Janeiro, 2010.

LAYRARGUES, P. P.; LIMA, G. F. C. Mapeando as macro-tendências político-pedagógicas da Educação Ambiental contemporânea no Brasil. In: VI Encontro Pesquisa em Educação Ambiental, 2011, Ribeirão Preto. VI Encontro Pesquisa em Educação Ambiental: a pesquisa em Educação Ambiental e a pós-graduação. Ribeirão Preto: USP, 2011. v. 0. p. 01-15. 2011. Disponível em <http://www.icmbio.gov.br/educacaoambiental/images/stories/biblioteca/educacao_ambiental/Layrargu es_e_Lima_-

Mapeando_as_macro tend\%C3\%83\%C2\%AAncias_da_EA.pdf >. Acesso em 2017-05-04.

LAYRARGUES, P. P.; LIMA, G. F. C. As macrotendências político-pedagógicas da Educação Ambiental brasileira. Ambiente \& Sociedade, v. XVII, n. 1, pp.23-40. 2014.

LIMA, M. J. G. S. O que fazem as escolas que fazem Educação Ambiental no Rio de Janeiro? Uma análise da pesquisa realizada pelo MEC/UFRJ/Anped à luz da teorização curricular. In: $30 a$ Reunião da Anped: 30 anos de pesquisa e compromisso social, 2007, Caxambu - MG. Anais da 30a Reunião Anual da Anped, p. 118. 2007.

LIMA, M. J. G. S. A disciplina Educação Ambiental na Rede Municipal de Educação de Armação de Búzios (RJ): investigando a tensão disciplinaridade/integração na política curricular. Tese (doutorado) - Universidade Federal do Rio de Janeiro, Faculdade de Educação, 2011.

LIMA, M. J. G. S.; SOARES, A. G.; FIGUEIRA, M. R. Educação Ambiental na Formação Inicial e Continuada de Professores: Articulando Ensino, Pesquisa e Extensão na UFRJ. In: Pedagogía 2015: encuentro internacional por la unidad de los educadores, 2015, Havana. Pedagogía 2015: encuentro internacional por la unidad de los educadores. p. 1-10. 2015

LOUREIRO, C. F. B. Trajetória e fundamentos da Educação Ambiental. São Paulo, Cortez, 2004.

LOUREIRO, C. F. B. Problematizando conceitos: contribuição à práxis em educação ambiental. In: LOUREIRO, C. F. B.; LAYRARGUES, P.P. e CASTRO, R. S. (orgs.) Pensamento complexo, dialética e Educação Ambiental. São Paulo: Cortez, 2006a.

LOUREIRO, C. F. B. Aspectos políticos e pedagógicos da educação ambiental no Brasil: um convite à reflexão. Revista Sinais Sociais, Rio de Janeiro, v. 1, n. 2, p. 44-83, set./dez. 2006b. Disponível em <http://www.sesc.com.br/wps/wcm/connect/9e034egd-479e-4acb-be2f-

a78653d3cd07/02.pdf?MOD=AJPERES\&CACHEID=9e034egd-479e-4acb-be2f-a78653d3cd07>. Acesso em 2018-08-01.

LOUREIRO, Carlos Frederico \& LIMA. M. J. G. S. A Educação Ambiental e a escola: uma tentativa de (re) conciliação. In: Paz, R.J. (Org.). Fundamentos, reflexões e experiências em Educação Ambiental. João Pessoa: Ed. Universitária/UFPB, 2006.

MAIA, J. S. S. Educação Ambiental sócio-histórica como perspectiva para a reflexão-ação sobre o trabalho pedagógico nos primeiros anos do ensino fundamental. In: TOZONI-REIS, M. F. C.; MAIA, J. S. S. (Orgs.). Educação Ambiental a várias mãos: educação escolar, currículo e políticas públicas. Araraquara, SP: Junqueira \& Marin, 2014.

NÓVOA, A. Para una formación de profesores construída dentro de la profesión. Revista de Educación, 350. Septiembre-diciembre 2009, pp. 203-218.

OLIVEIRA, C. S. Educação Ambiental na escola: diálogos com as disciplinas escolares ciências e biologia. Dissertação de Mestrado. Universidade Federal do Rio de Janeiro - Faculdade de Educação. 2007

PARANHOS, R. D.; SCHUVARTZ, M. A Relação Entre Educação Ambiental e a Educação de Jovens e Adultos Sob a Perspectiva da Trajetória dos Educadores. Contexto \& Educação, Editora Unijuí Ano 28 n 91 Set./Dez. 2013.

SELLES, S.E. Quando as políticas curriculares e a pesquisa educacional mandam: reflexões sobre a colonização do trabalho docente. Boletim Gepem , № 67 - Jul. / Dez. 2015 
SELLES, S. E.; FERREIRA, M. S. Saberes docentes e disciplinas escolares na formação de professores em Ciências e Biologia. In: SELLES, S. E. et al. (Orgs.). Ensino de Biologia: histórias, saberes e práticas formativas. Uberlândia: EdUFU. p. 49-69. 2009.

SILVA, E. W. A extensão universitária no Brasil. In: SILVA, E. W. \& FRANTZ, W. A extensão universitária no Brasil. As funções sociais da Universidade: o papel da extensão e a questão das comunitárias. ljuí: Ed. Unijuí. 2002.

SILVA, R. L. F.; CAMPINA, N. N. Tipologia de análise de concepções de Educação Ambiental: possibilidades e limites para o reconhecimento da pluralidade da área. In: $V$ Encontro de Pesquisa em Educação Ambiental, 2009, São Carlos. Anais do V EPEA. São Carlos: UFSCAR, p. 70-84. 2009. Disponível em <http://www.epea.tmp.br/epea2009_anais/pdfs/plenary/To4.pdf>. Acesso em 2017-05-04.

TARDIF, M. Saberes Docentes e Formação Profissional. Petrópolis, RJ: Vozes, 2014.

TREIN, E. Educação Ambiental Crítica: Crítica de quê? Revista Contemporânea de Educação, vol. 7, n. 14, agosto/dezembro de 2012. Disponível em: <https://revistas.ufrj.br/index.php/rce/article/view/1673/1522>. Acesso em 8 nov. 2018.

TRAJBER, R.; MENDONÇA, P. R. Introdução. In: TRAJBER, R.; MENDONÇA, P. R. (Orgs.). Educação na diversidade: 0 que fazem as escolas que dizem que fazem Educação Ambiental. Brasília: Secretaria de Educação Continuada, Alfabetização e Diversidade, 2007. 